\title{
Presence of undeclared caffeine in weight loss food supplements.
}

\author{
Stanislava Ivanova ${ }^{1}$, Anna Mihaylova ${ }^{2}$, Penka Petleshkova ${ }^{2 *}$, Kalin Ivanov ${ }^{1}$ \\ ${ }^{1}$ Department of Pharmacognosy and Pharmaceutical Chemistry, Medical University of Plovdiv, Bulgaria \\ ${ }^{2}$ Medical college, Medical University of Plovdiv, Bulgaria
}

\begin{abstract}
Recent studies claim that weight loss supplements often contain pharmacoactive ingredients or undeclared drug substances with a potential health risk. This study is focused on food supplements in the category "weight loss" in which label caffeine was not declared. Analysed samples were purchased from dietary supplement stores, pharmacies and internet. In the screening were included only food supplements witch do not contain caffeine or herbal extracts which contain caffeine like guarana, kola nut, yerba mate etc. 30 samples were analysed by HPLC/UV detection. We found undeclared caffeine in 5 of the analysed samples. The presence of undeclared caffeine in food supplements for weight loss could lead to serious health consequences especially for consumers with cardiovascular diseases.
\end{abstract}

Keywords: Caffeine, Food supplements, HPLC caffeine, Undeclared substances, Weight loss foot supplements, Obesity.

Accepted on March 22, 2019

\section{Introduction}

During the past three decades obesity and overweight have become major challenges to chronic disease prevention and health worldwide [1-6]. Obesity is a rapidly growing serious health problem affecting an increasing number of people all over the world. It is considered not only as an abnormal accumulation of body fat but it could cause serious adverse effect on health [1-5]. The long-term health consequences include: development of diabetes, coronary heart disease, depression, respiratory complications, non-alcoholic fatty liver disease, joint pain, osteoarthritis and others [2]. Excess body weight is also an important risk factor for mortality and morbidity from cardiovascular diseases [5]. The measure of obesity is the body mass index (BMI). A person with a BMI-30 or more is considered obese. A person with a $\mathrm{BMI} \leq 25$ is considered overweight [7]. According to the World Health Organisation (WHO) worldwide, the number of obesity people has nearly tripled since 1975 . Nowadays more than 1.9 billion adults are overweight of them over 650 million are obese [8]. This problem is rising at an alarming pace not only in adult population [9].

According to the World Health Organisation (WHO) the number of overweight/obese infants and young children (aged 0 to 5 years) increased from $32,000,000$ globally in 1990 to $41,000,000$ in 2016 [8]. WHO predicts that if these trends continue the number of overweight or obese infants and young children will have increased to 70 million by 2025 .

Overweight and obesity are preventable conditions. The most efficient way is the combination of healthy foods (low calorie intake) and regular physical activity. The food industry could also play an important role in prevention from obesity by reducing the fat, sugar and salt content of complementary foods and also by practicing responsible marketing [8]. One of the most popular weight loss approaches is the intake of food supplements. Some of the most used categories of food supplements for reduction of the weight are summarised in Table 1. Food supplement intake could have beneficial effects for losing weight if it is combined with physical activity and low calorie diet but it hides some risks. Even most of the people consider food supplements as safe products with no side effects, not all of them are safe enough. For example food supplements for weight loss containing caffeine or some other substances could be dangerous for patients with cardiovascular disease. Moreover many researchers have found undeclared substances in food supplements-about $20 \%$ of the analysed samples have been found to contain undeclared substances like caffeine, sibutramine, steroids and others [10-18,19].

Weight loss strategy for obese people should be carefully done and supplementation should be recommended by a physician or another medical specialist, because most of these patients suffer from coronary heart disease and other serious medical conditions.

According to European Pharmacopeia caffeine (Figure 1) is a white or almost white, crystalline powder or silky, white or almost white, crystals. It is sparingly soluble in water, freely soluble in boiling water, slightly soluble in ethanol [20]. 
It presents in the composition of many drugs, in combination with other drug substances like paracetamol, ibuprofen and others. These medicines are mainly used as pain relievers.

Caffeine is a substance included also in many food supplements for weight loss with the purpose of increasing thermogenesis and lipid metabolism [18].

Caffeine administration affects the functioning of the cardiovascular, respiratory, renal, and nervous systems [21].

If it is declared on the label of a particular food supplement the product would not be included in the diet of an obese patient because of the high risk of increasing blood pressure, pulse rate and others. It is extremely dangerous for the patients the presence of undeclared caffeine in food supplements. That could expose consumers to possible side-effects and drug interactions. Researchers consider that inclusion of any unlabelled substance could be motivated by a desire to increase or alter the claimed effect of the product $[9,11]$ but it could also happen because of non-compliance of GMP guidelines. In both cases it is a problem and it is dangerous for consumers.<smiles>Cn1c(=O)c2c(ncn2C)n(C)c1=O</smiles>

Figure 1. Caffeine structure.

Table 1. Weight-loss food supplements.

\begin{tabular}{|c|c|c|c|}
\hline Ingredients & Benefits for weight loss process & $\begin{array}{l}\text { Scientific } \\
\text { evidences }\end{array}$ & Safety \\
\hline L-carnitine & $\begin{array}{l}\text { Transports fatty acids into } \\
\text { mitochondria for oxidation [22] }\end{array}$ & $\begin{array}{l}\text { Not enough } \\
\text { evidences }\end{array}$ & Safe \\
\hline Garcinia cambogia & Reduction of appetite [23] & $\begin{array}{l}\text { Limited number } \\
\text { of researches }\end{array}$ & Not enough evidences \\
\hline Yohimbine & $\begin{array}{l}\text { Significant increase in energy } \\
\text { expenditure }[24,25]\end{array}$ & $\begin{array}{l}\text { Limited number } \\
\text { of researches }\end{array}$ & $\begin{array}{l}\text { Yohimbine intake could cause: increase of blood pressure and pulse rate, headache, } \\
\text { flush, sweating, anxiety, agitation and many other side effects }\end{array}$ \\
\hline $\begin{array}{l}\text { Caffeine containing } \\
\text { food supplements }\end{array}$ & $\begin{array}{l}\text { Modest reduction of weight loss } \\
\text { [26-28] Diuretic effect }\end{array}$ & $\begin{array}{l}\text { More studies } \\
\text { should be done }\end{array}$ & Increase of blood pressure and pulse rate, tremor, insomnia \\
\hline Biotin & Not enough evidences. & $\begin{array}{l}\text { Not enough } \\
\text { evidences }\end{array}$ & Not enough evidences \\
\hline Chitosan & Prevents fat absorption [28] & $\begin{array}{l}\text { Not enough } \\
\text { evidences }\end{array}$ & Not enough evidences \\
\hline $\begin{array}{l}\text { Anti-cellulite draining } \\
\text { food supplements }\end{array}$ & Diuretic effect & $\begin{array}{l}\text { Limited number } \\
\text { of researches }\end{array}$ & Not enough evidences \\
\hline Others & - & - & - \\
\hline
\end{tabular}

\section{Material and Methods}

\section{Materials}

Reference standard: Caffeine (Sigma Aldrich).

Reagents: Methanol for HPLC (Sigma Aldrich); Deionised water.

Samples: 30 food supplements with beneficial effects on weight loss. Samples were purchased from dietary supplement stores, pharmacies, and internet.

\section{Methods}

HPLC/UV detection: Instrumentation: Varian Pro Star HPLC system, UV detector, chromatographic column-Microsorb-MV 100-5 C18 $150 \times 4.6 \mathrm{~mm}$, Hamilton syringes designed for use with manual HPLC injection ports $(25 \mathrm{mcl})$.
Chromatographic conditions: Mobile phase A: Water, Mobile phase B: Methanol, Elution: 70\% mobile phase A, 30\% mobile phase B, Flow rate: $1 \mathrm{ml} /$ minute, UV detector set at $273 \mathrm{~nm}$.

\section{Results and Discussion}

Recent studies claim that weight loss supplements often contain active pharmacoactive ingredients or undeclared drug substances with a potential health risk [29,30]. This study is focused on food supplements in the category "weight loss" in which label caffeine was not declared. Analysed samples were purchased from dietary supplement stores, pharmacies and internet. We divided the samples in four categories: L-carnitine containing food supplements $(\mathrm{n}=10)$, yohimbine containing $(n=4)$, biotin containing food supplements $(n=4)$, others $(n=12)$. We observed the label of selected food supplementsthe statement of identity, nutrition labelling, ingredient labelling, and nutrient content. In the screening were included 
only food supplements witch do not contain caffeine, or herbal extracts which contain caffeine-like guarana, kola nut, yerba mate etc.

For the screening we used Varian Pro Star HPLC system: chromatographic column-Microsorb-MV 100-5 C18 $150 \times 4.6$ $\mathrm{mm}$ and UV detector. The UV detector was set at $273 \mathrm{~nm}$. Mobile phase: water $70 \%$, methanol $30 \%$. The analytical procedure was simple and accurate. It was previously validated.

\section{Standard solution of caffeine}

$6.0 \mathrm{mg}$ of referent substance caffeine (Sigma Aldrich) was weighed in a volumetric flask $(10 \mathrm{ml})$. The substance was dissolved in $2 \mathrm{ml}$ methanol. We added to the solution $8 \mathrm{ml}$ deionised water. Concentration of the stock solution- 600 $\mu \mathrm{g} / \mathrm{ml}$. Caffeine working solution was prepared by dilution of the stock solution. Concentration of the working solution-60 $\mu \mathrm{g} / \mathrm{ml}$.

Samples preparation included extraction with methanol and dilution with water/methanol $(2 / 8 \mathrm{v} / \mathrm{v}) .30$ working test solution were prepared by dilution of the test stock solutions. All test solutions were filtrated twice. The first step included prefiltration to remove larger particles from the solutions. After that it was performed subsequent, finer filtration. We used syringe filters (pore size $0.45 \mu \mathrm{m}$ ). All samples were introduced in the chromatographic system through manual injector port. We used Hamilton Syringes for HPLC (25 mcl.). Injection-20 mcl of each sample.

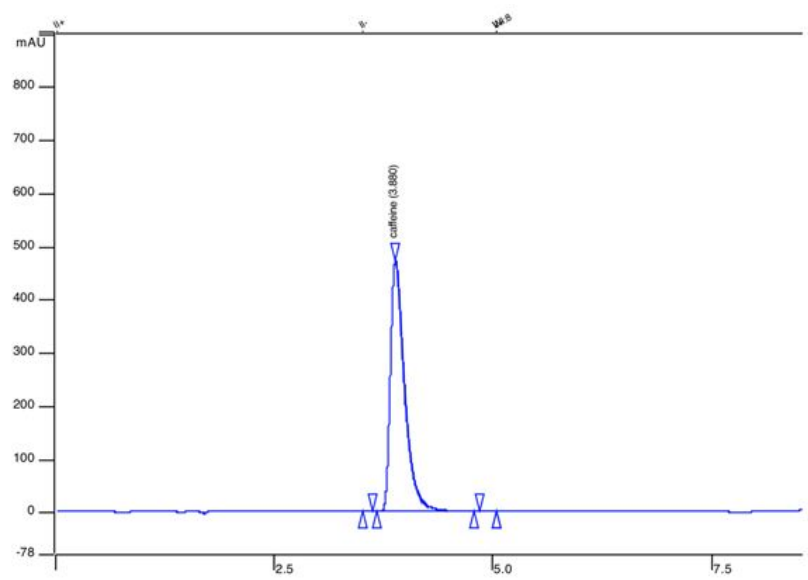

Figure 2. Chromatogram of standard solution of caffeine, $R T=3.88$ minutes.

We established retention time for caffeine standard 3.88 minutes (Figure 2). Figure 2 represents chromatogram of standard solution of caffeine. We found that 5 of the analysed samples contained undeclared caffeine in concentration from $10 \mathrm{mg}$ per capsule up to $90 \mathrm{mg}$. Figure 3 presents overlaid chromatograms of the caffeine-positive samples. The food supplement in which content we found $90 \mathrm{mg}$ caffeine per capsule was labelled: 1 capsule 2 times daily. That means that a consumer of that product would take about $180 \mathrm{mg}$ caffeine per day without knowing. The administration of single dose of
$200 \mathrm{mg}$ of caffeine could significantly increase blood pressure [18] and could lead to some serious effects. The intake of undeclared caffeine in the late afternoon could lead to insomnia. Although we did not find caffeine in high doses in the analysed samples, the intake of undeclared caffeine could cause issues when it is combined with coffee and other highcaffeine beverages. The results of this study indicate that weight loss supplements could contain undeclared substances and the intake of these products could expose at serious risk individuals with heart disease.

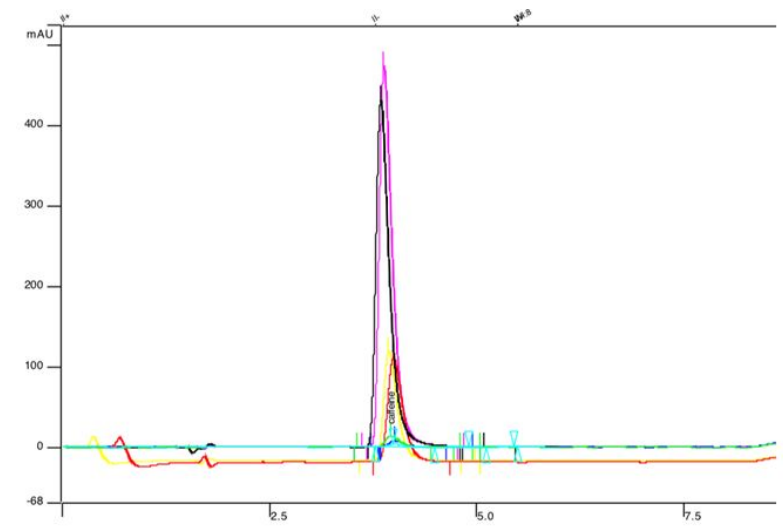

Figure 3. Overlaid chromatograms of caffeine-positive samples.

\section{Conclusion}

Recent studies claim that more than $20 \%$ of weight loss food supplements could contain undeclared substances that could represent a potential health risk. We analysed 30 food supplements for weight loss for undeclared caffeine. We found that 1 in 6 contained undeclared caffeine (total 5 from 30) $16.66 \%$. Most of obese and overweight people suffer from hypertension. We consider that it is very dangerous for patients with cardiovascular diseases to take food supplements with undeclared caffeine because this could lead to serious health consequences.

\section{References}

1. Hruby A, Hu FB. The epidemiology of obesity: A big picture. Pharmacoeconomics 2015; 33:673-689.

2. Agha M, Agha R. The rising prevalence of obesity: part A: impact on public health. Int J Surg Oncol (NY) 2017; 2:e17.

3. Ng M, Fleming T, Robinson M, Thomson B, Graetz N, Margono C, Mullany EC, Biryukov S, Abbafati C, Abera $\mathrm{SF}$, Abraham JP Global, regional, and national prevalence of overweight and obesity in children and adults during 1980-2013: a systematic analysis for the global burden of disease study 2013. Lancet 2014; 384:766-781.

4. Stevens GA, Singh GM, Lu Y, Danaei G, Lin JK, Finucane MM, Bahalim AN, McIntire RK, Gutierrez HR, Cowan M, Paciorek CJ, Farzadfar F, Riley L, Ezzati M. Global burden of metabolic risk factors of chronic diseases collaborating group (Body Mass Index). 
National, regional, and global trends in adult overweight and obesity prevalences. Popul Health Metr 2012; 10:22.

5. Finucane MM, Stevens GA, Cowan MJ, Danaei G, Lin JK, Paciorek CJ, Singh GM, Gutierrez HR, Lu Y, Bahalim AN, Farzadfar F, Riley LM, Ezzati M. Global burden of metabolic risk factors of chronic diseases collaborating group (Body Mass Index). National, regional, and global trends in body-mass index since 1980: systematic analysis of health examination surveys and epidemiological studies with 960 country-years and $9 \cdot 1$ million participants. Lancet 2011; 377:557-567.

6. Wang Y, Beydoun MA. The obesity epidemic in the United States--gender, age, socioeconomic, racial/ethnic, and geographic characteristics: a systematic review and meta-regression analysis. Epidemiol Rev 2007; 29:6-28.

7. https://ods.od.nih.gov/factsheets/weightlosshealthprofessional/

8. https://www.who.int/topics/obesity/en/

9. Allcock DM, Gardner MJ, Sowers JR. Relation between childhood obesity and adult cardiovascular risk. Int $\mathrm{J}$ Pediatr Endocrinol 2009: 108187.

10. Belza A, Toubro S, Astrup A. The effect of caffeine, green tea and tyrosine on thermogenesis and energy intake. Eur J Clin Nutr 2009; 63:57-64.

11. Neves DBDJ, Caldas ED. Determination of caffeine and identification of undeclared substances in dietary supplements and caffeine dietary exposure assessment. Food Chem Toxicol 2017; 105:194-202.

12. Baume N. Research of stimulants and anabolic steroids in dietary supplements. Scand J Med Sci Sports 2006; 16:41-48

13. Thuyne WV, Eenoo, VP, Delbeke FT. Nutritional supplements: prevalence of use and contamination with doping agents. Nutr Res Rev 2006; 19:147-158.

14. Green GA, Catlin DH, Starcevic B. Analysis of over-thecounter dietary supplements. Clin J Sport Med 2001; 11:254-259.

15. Mathon C, Ankli A, Reich E, Bieri S, Christen P. Screening and determination of sibutramine in adulterated herbal slimming supplements by HPTLC-UV densitometry. Food Addit Contam Part A Chem Anal Control Expo Risk Assess 2014; 31:15-20.

16. Parr MK, Geyer H, Reinhart U, Schänzer W. Analytical strategies for the detection of non-labeled anabolic androgenic steroids in nutritional supplements. Food Addit Contam 2004; 2:632-640.

17. Kamber M, Baume N, Saugy M, Rivier L. Nutrtional supplements as a source for positive doping cases? Int J Sport Nutr Exerc Metab 2001; 1:258-263.

18. Viana C, Zemolin GM, Molin TRD, Gobo L, Rebeiro SM, Leal GC, Marcon GZ, de Carvalho LM. Detection and determination of undeclared synthetic caffeine in weight loss formulations using HPLC-DAD and UHPLCMS/MS. JPA 2018; 8:366-372.
19. Müller D, Wolfgang W, Maren HC. Chinese slimming capsules containing sibutramine sold over the Internet: a case series. Dtsch Arztebl Int 2009; 106:218-222.

20. Council of Europe. European Pharmacopoeia (Ph. Eur). 9th Edition.

21. National Research Council. Caffeine for the sustainment of mental task performance: Formulations for military operations. Washington DC National Academy Press 2001; 6:104-168.

22. Brandsch C, Eder K. Effect of L-carnitine on weight loss and body composition of rats fed a hypocaloric diet. Ann Nutr Metab 2002; 46:205-210.

23. Fassina P, Scherer AF, Terezinha ZV, Kasper MIC, Garavaglia J, Quevedo GMT, Ramos R, Morelo DBS. The effect of Garcinia Cambogia as coadjuvant in the weight loss process. Nutri Hosp 2015; 32: 2400-2408.

24. Zito G, Cambell B, Colquhoun R, Martinez N, Buchanan L, Lehn M, Johnson M, St Louis C, Smith Y, Cloer B, Pingel A. The effects of a fat loss supplement on resting metabolic rate and hemodynamic variables in healthy females: preliminary results. JISSN 2014; 11:1.

25. Campbell B, Colquhoun RJ, Zito G, Martinez N, Kendall K, Buchanan L, Lehn M, Johnson M, St Louis C, Smith Y, Cloer B. The effects of a fat loss supplement on resting metabolic rate and hemodynamic variables in resistance trained males: a randomized, double-blind, placebocontrolled, cross-over trial JISSN 2016; 13:14.

26. Westerterp PMS, Lejeune MP, Kovacs EM. Body weight loss and weight maintenance in relation to habitual caffeine intake and green tea supplementation. Obes Res 2005; 13:1195-1204.

27. Petrie HJ, Chown SE, Belfie LM, Duncan AM, McLaren $\mathrm{DH}$, Conquer JA, Graham TE. Caffeine ingestion increases the insulin response to an oral-glucose-tolerance test in obese men before and after weight loss. Am J Clin Nutr 2004; 80:22-28.

28. Hursel R, Viechtbauer W, Plantenga WMS. The effects of green tea on weight loss and weight maintenance: a metaanalysis. Int J Obes 2009; 33:956.

29. Lobb A. Science of weight loss supplements: compromised by conflicts of interest? World J Gastroenterol 2010; 16:4880-4882.

30. Viana C, Zemolin GM, Dal Molin TR, Gobo L, Ribeiro SM, Leal GC, Marcon GZ, de Carvalho LM. Detection and determination of undeclared synthetic caffeine in weight loss formulations using HPLC-DAD and UHPLCMS/MS. J Pharm Anal 2018; 8:366-372.

\section{*Correspondence to}

Penka Petleshkova

Medical college

Medical University of Plovdiv

Bulgaria 